\title{
Revisiting Global Health Security Measures in COVID 19 Pandemic Suneela Garg ${ }^{1}$, Nidhi Bhatnagar ${ }^{2}$, Ekta Arora ${ }^{3}$, Pradeep Aggarwal ${ }^{4}$
}

${ }^{1}$ National President, Indian Association of Preventive and Social Medicine, Director Professor, Department of Community Medicine, Maulana Azad Medical College, New Delhi; ${ }^{2}$ Assistant Professor, Department of Community Medicine, Maulana Azad Medical College, New Delhi; ${ }^{3}$ Assistant Professor, Department of Community Medicine, Lady Hardinge Medical College, New Delhi; ${ }^{4}$ Associate Professor, Department of Community Medicine, All India Institute of Medical Sciences, Rishikesh

\section{Corresponding Author}

Dr. Ekta Arora, Assistant Professor, Department of Community Medicine, Lady Hardinge Medical College, New Delhi- 110001.

E Mail ID: aroraekta09@gmail.com

\section{Citation}

Garg S, Bhatnagar N, Arora E, Aggarwal P. Revisiting Global Health Security Measures in COVID 19 Pandemic. Indian J Comm Health. 2021;33(2):407-410. https://doi.org/10.47203/IJCH.2021.v33i02.035

Source of Funding: Nil Conflict of Interest: None declared

\section{Article Cycle}

Received: 07/06/2021; Revision: 15/06/2021; Accepted: 22/06/2021; Published: 30/06/2021

This work is licensed under a Creative Commons Attribution 4.0 International License.

\section{Abstract}

As the world has become a global village with increasing socio-economic interdependence, health, security and stability issues are imposing interrelated global impacts. Thus, activities supporting epidemic and pandemic preparedness are needed to minimize vulnerability to acute public health events. Coordination mechanisms must be pre-established for diagnostics, therapeutics and research as emergencies often lead to competition and shortage of resources. This paper attempts to discuss the available global health security measures at the time of COVID 19 pandemic.

\section{Keywords}

Global Health Security, Global Health Security Agenda, International Health Regulations, Emergency Preparedness protected from health emergencies and One billion more people enjoying better health and well-being.(1) To

Emerging and re-emerging diseases e.g. Ebola in 2016, Nipah in 2018 and SARS CoV 2 in 2019, are impacting health and socio-economic parameters globally. The world has become a global village with increasing socioeconomic interdependence. It has been increasingly understood that health, security and stability issues have interrelated global impacts, thus requiring a transnational approach to mitigate the upcoming threats. There is a felt need to understand the emerging health threats and respond globally in a coordinated manner. Systems must be in place for early detection, prompt response and mitigation measures. Coordination mechanisms must be pre-established for diagnostics, therapeutics and research as emergencies often lead to competition and shortage of resources. This is an attempt to discuss the available global health security measures at the time of COVID 19 pandemic.

The Thirteenth General Program of Work (GPW 13) defines WHO's strategy for the five-year period, 20192023. It focuses on measurable impacts on people's health at country level; One billion more people to benefit from universal health coverage, One billion more people better achieve the committed target of health emergency, new WHO Health Emergencies Program was reformed based on the West Africa Ebola Outbreak. Increased core capacities in Africa, Asia and Middle East was prioritized with standardization of country level response and engaging close participation with GOARN (Global Outbreak Alert Response Network). GOARN 2.0 has now emphasized on the risk assessment and pre-pandemic preparedness along with working on pandemic response measures.

Global Health Security is defined as the activities required, both proactive and reactive, to minimize the danger and impact of acute public health events that endanger people's health across geographical regions and international boundaries.It contributes indispensably in the implementation of new resilience measures.(2) Activities supporting epidemic and pandemic preparedness and enhancing capabilities at the country and global level are needed to minimize vulnerability to acute public health events that can endanger the health of populations across geographical regions and international boundaries.(3) 
GHS assessed country's health systems efficiency and capacity for prevention, early detection and appropriate responsiveness to the unforeseen health emergencies. 2019 GHS Index projects that world is still unprepared for outbreaks of major infectious diseases. To aim for stronger health security, countries should focus on factors like effective governance and a strong disease surveillance system. More than 100 high- and middle-income countries scored below 50 in the index.(4) 27 and 73 out of 195 countries were identified as more and most vulnerable to emerging outbreaks.(5)

The Global health Security Initiative (GHSI), launched in 2001 is an informal partnership between countries and organizations to strengthen public health preparedness and response to threats of CBRN (Chemical, Biological, Radiological, Nuclear) terrorism as well as pandemic influenza. Members are Canada, the European Commission, France, Germany, Italy, Japan, Mexico, the United Kingdom and the United States with World Health Organization being a technical advisor. GHSI members meet regularly to set priorities for the year, discuss emerging threats to health security, and plan joint action to protect global populations.(6)

The Global Health Security Agenda (GHSA), launched in Feb. 2014 by nearly 30 countries and international organizations, is serving as a catalyst to achieve the vision of a safe world free from the threats posed by infectious diseases.(7) The vision is for an effective, universal interconnection of stakeholders involved in mitigating global health security challenges, with a focus on strengthening health systems.(8) India is one of the active members of GHSA Steering Group along with 65 participating countries, 9 international and regional multilateral organizations, over 100 private companies, non-governmental organizations, and academic institutions.

Global Health Security Agenda (GHSA) with CDC attempts rational upgradation in public health emergency management through disease tracking, surveillance systems, training of the manpower and other measures. CDC is workingto prevent the avoidable catastrophes through measures like Immunization, Biosafety, Spreading Awareness and capacity building of resources. It focusses to detect threats in an early stage through massive surveillance and tracking system andrespond rapidly and effectively through improved medical measures and trained personnel.(9)

International Health Regulations aims to prevent, protect against, control and provide a public health response to the international spread of disease in ways that are commensurate with and restricted to public health risks, and which avoid unnecessary interference with international traffic and trade. The regulations emphasize that the countries should have the ability to detect, assess, report and respond to public health events by building up the core competencies.
Both GHSA and the IHR focuses to achieve the above goal by encouraging political commitment and participation, coordination, and collaboration by multiple stakeholders.(10) IHR also provides legal basis for important health documents applicable to international travel, transport and sanitary protection for the users of international airports, ports, and ground crossings.

IHR (2005) serves as a foundation for the Global Health Security Agenda which provides 11 clear targets to help countries create systems to prevent, detect and respond to health threats. "Action Packages" concept was developed to facilitate regional and global collaboration toward specific GHSA objectives and targets.(11) GHSA Commitment Development meeting in 2011 identified eleven discrete GHSA Action Packages, which were discussed further at the Global Infectious Diseases Meeting 2014 in Jakarta. These 11 action packages are drafted based on current and future health threats; Zoonotic Disease Action Package, Biosafety and biosecurity Action Package, Antimicrobial Resistance, Immunization Action Package, Emergency Operations Centers Action Package, Linking Public Health with Law and Multisectoral Rapid Response Action Package, Medical Countermeasures and Personnel Deployment Action Package, National Lab System Action Package and Real Time Surveillance Action Package, Reporting Action Package.

Measurement of status of nations in terms of health security was undertaken by GHSA through various voluntary and involuntary assessments. The IHR Monitoring and Evaluation Framework is made up of the States Parties Self-Assessment Annual Reporting (SPAR) ; the voluntary external evaluation; the After Action Review (AAR); and Simulation Exercises (SimEx).(12) The evaluation findings of one or all components, considered alongside the results of other assessments (such as risk profiling), can serve as a basis for countries to develop and implement national action plans for health security (NAPHS)

SPARtool consists of 24 indicators for the 13 IHR capacities needed to detect, assess, notify, report and respond to public health risk and acute events of domestic and international concern.(13) It is a country's self assessment report to be submitted annuallyto encourage the transparency and mutual accountability between States Parties towards global public health security, under the WHO IHR Monitoring and Evaluation Framework. It provides useful information and follow up for GPW 13 indicator on emergency preparedness; and UN SDG Goal 3 for indicator 3.d.1 - International Health Regulations (IHR) capacity and health emergency preparedness.Close coordination between the health system and health security is required to bring coordination between Universal Health Coverage and Global Health Security.(14) After Action Reviews (AAR)\&Simulation Exercises (SimEx) have been identified as a key voluntary instrument in the 
validation of core capacities under the implementation of the International Health Regulations. Simulation exercises, along with After Action Reviews, represent the functional assessment of capacities and complement States Parties annual reporting, independent reviews, and joint external evaluations.(15) They play a key role in identifying the strengths and gaps in the development and implementation of IHR capacities and to support countries to assess the operational capability of their national capacity for public health preparedness and response.

An AAR is an in-depth review, a structured approach of the response actions taken during an actual public health event, done subsequently in order to identify gaps, lessons and best practices. It offers individuals and organizations involved in preparedness and response to the event, to reflect on their experiences and their perceptions of the response.(16) A SimEx is a form of practice, training, monitoring or evaluation of capabilities, and involves the description or simulation of an emergency to which a described or simulated response is made. Simulation exercises can provide evidence-based assessments of functional capacity to respond to emergencies and strengthen preparedness and response.(17)

The Joint External Evaluation (JEE) is a voluntary and comprehensive process to evaluate country capacity across 19 technical areas, to address infectious disease risks through a coordinated response.Through the JEE, countries can identify the critical gaps within their health systems,prioritize opportunities for enhanced preparedness and engage with partners to effectively target resources.(18) In South East Asian Region, 7 of 11 countries have undergone JEE assessments.

\section{GHSA and India:}

In June 2016, Indo-US joint statement reaffirmedcommitment to Global Health Security Agenda(GHSA) and timely implementation of its objectives. In August 2016, India-U.S. Strategic and Commercial Dialogue, reconfirmed their expanding collaboration on the GHSA focusing specifically on the 'Core 4' public health functions:

1. Increasing real-time surveillance of potential public health threats,

2. Strengthening laboratory systems,

3. Capacity Building and skill training of health workers

4. Building rapid response teams capable of activating a coordinated emergency response.

India's GHSA projects are implemented through institutional partners, including NCDC, MCVR (Manipal Centerfor Virus Research) and NIV (National Institute of Virology)/ICMR.

India is signatory to WHO's International Health Regulations 2005, which provides India with an additional incentive for health system strengthening and capacity building efforts.India has actively contributed to two action packages; Antimicrobial Resistance and
Immunization Action Package. As per IHR-MEF, India has not been a part of Joint External Evaluations but is regularly submitting the annual SPAR data. India fairs poor in the Global Health security index ranking with 57th position compared to other countries and a cumulative score of 46.5 and is placed in the middle (more prepared) category. Based on the latest annual reporting data in 2019 , top challenges identified for national health security were Health Service Provision (33\%), Zoonotic events, health human interface (60\%), Food Safety (60\%) and Laboratory services (67\%).

Under GHSA partnership, in August 2017, the US CDC provided training to participants from MCVR and NIV to increase diagnostic capacity and enhance skills to investigate causes of acute febrile illnesses. It shared technical expertise, specific reagents and training for diagnosis of dangerous viruses including Nipah and Crimean-Congo hemorrhagic fever through techniques like NGS (Next Generation Sequencing) analysis technology. During Nipah Outbreak in 2018, these skills, including NGS, were utilized by scientists at MCVR to detect NiV as the pathogen responsible without requiring sample transport outside of India. This early detection helped the governments to respond to Nipah more quickly, thus limiting the severity of the outbreaks in terms of loss of life and commerce.(19)

In National Center of Disease Control, creation of trained manpower in the form of EIS (Epidemic Intelligence Services) has been done to support epidemic response measures at state level. This is expected to expand and support the national health security agenda.(20) Integrated disease surveillance platform has been refined to Integrated health Information Platform where the automated data will help in a big way in real-time data collection. It will assist in analysis, data aggregation and allow evidence-based policymaking. Advanced digital platform will enable identifying the earliest signs of disease spread in small blocks or villages and will be extremely helpful in investigating any potential outbreak or epidemic.

\section{Recommendations \& Conclusions}

This next phase of GHSA, "GHSA 2024," aims to be strategic with efficient governance and clear accountability in meeting the commitments. GHSA 2024, thus focuses to follow a multisectoral approach to address the gaps and to introduce sustainable financing for global health security efforts.Capacity building of the manpower, financial sustainability, transparent collaboration between countries are needed to strengthen global readiness for outbreak control.Thus, the focus for emergency preparedness should be on an elaborative surveillance, rapidly acting public health system and infrastructure including wide laboratory network and a trained epidemiologic workforce.(21) 
India needs to step up measures to address national health security. Health policy belongs to the national security domain and different stakeholders outside health must engage on the same. WHO and international bodies have made available required guidance document and measurement tools. GHS 2021 will be available later this year that attempts to incorporate important lessons learned from COVID-19 and will continue as an international benchmark for capacity and capability in times of global disaster. There is an urgent need to utilize these aids and have national strategic health action plan in place along with working on the public health care system and making it resilient. Financing public health sector must be prioritized to meet the requirements and targets set by GHSA 2024. The current crisis is an opportunity for countries like India to recast its health diplomacy and fork out a new vision for India's role in world health.

\section{References}

1. Thirteenth General Programme of Work 2019-2023.. Available from: $\quad$ https://www.who.int/about/what-we-do/thirteenthgeneral-programme-of-work-2019---2023 (accessed on 25.06.2021

2. Heymann DL, Chen L, Takemi K, Fidler DP, Tappero JW, Thomas MJ, et al. Global health security: the wider lessons from the west African Ebola virus disease epidemic. The Lancet. 2015;385(9980):1884-901.

3. Health security.. Available from: https://www.who.int/healthtopics/health-security/\#tab=tab_1 (accessed on 25.06.2021)

4. Sharma NC. World unprepared for infectious disease outbreaks, India ranks low at 57. Livemint. 2019 [cited 2020 Jun 2]. Available from: https://www.livemint.com/news/india/world-unpreparedfor-infectious-disease-outbreaks-india-ranks-low-at-5711571984349220.html (accessed on 25.06.2021)

5. COVID-19: Identifying the Most Vulnerable Countries Using the GHS Index and Global Flight Data | NTI.. Available from: https://www.nti.org/analysis/articles/covid-19-identifying-mostvulnerable-countries-using-ghs-index-and-global-flight-data/ (accessed on 25.06.2021)

6. Foley M. Home. Global Health Security Initiative. Available from: http://ghsi.ca/ (accessed on 25.06.2021)

7. .The U.S. Government and Global Health. KFF. 2019. 2019 Jul 30 P. Available from: https://www.kff.org/global-health-policy/factsheet/the-u-s-government-and-global-health/ (accessed on 25.06.2021)
8. Global Health Security Alliance - Global Health Security Alliance The Nexus between Global Health and Global Security.. Available from: https://glohsa.com/ (accessed on 25.06.2021)

9. CDC Global Health - CDC and the Global Health Security Agenda. 2020. Available from: https://www.cdc.gov/globalhealth/security index.htm (accessed on 25.06.2021)

10. Katz R, Sorrell EM, Kornblet SA, Fischer JE. Global Health Security Agenda and the International Health Regulations: Moving Forward Biosecurity Bioterrorism Biodefense Strategy Pract Sci. 2014;12(5):231-8.

11. CDC Global Health - Global Health Security Agenda: Action Packages. 2019. Available from: https://www.cdc.gov/globalhealth/security/actionpackages/defau It.htm (accessed on 25.06.2021)

12. Stoto MA, Nelson C, Piltch-Loeb R, Mayigane LN, Copper F, Chungong $S$. Getting the most from after action reviews to improve global health security. Glob Health. 2019;15(1):58.

13. WHO | State Party self-assessment annual reporting tool. WHO. Available from: http://www.who.int/ihr/publications/WHO-WHECPI-2018.16/en/

14. Kluge H, Martín-Moreno JM, Emiroglu N, Rodier G, Kelley E, Vujnovic $M$, et al. Strengthening global health security by embedding the International Health Regulations requirements into national health systems. BMJ Glob Health. 2018;3(Suppl 1):e000656.

15. WHO | Simulation Exercise [Internet]. WHO. [cited 2020 Jun 2]. Available from: http://www.who.int/ihr/procedures/simulationexercise/en/ (accessed on 25.06.2021)

16. Savoia E, Agboola F, Biddinger PD. Use of After Action Reports (AARs) to Promote Organizational and Systems Learning in Emergency Preparedness. Int J Environ Res Public Health. 2012;9(8):2949-63.

17. Simulation Exercise | Strategic Partnership for IHR and Health $\begin{array}{llll}\text { Security } & \text { (SPH). Available from: }\end{array}$ https://extranet.who.int/sph/simulation-exercise (accessed on 25.06.2021)

18. WHO Joint External Evaluations. Available from: https://www.who.int/ihr/procedures/joint-externalevaluations/en/ (accessed on 25.06.2021)

19. Sadanadan R, Arunkumar G, Laserson KF, Heretik KH, Singh S, Mourya DT, et al. Towards global health security: response to the May 2018 Nipah virus outbreak linked to Pteropus bats in Kerala, India. BMJ Glob Health. 2018;3(6):e001086.

20. Narain JP. India epidemic intelligence service: Advocating for a unique mentor-based epidemiology training program. Indian J Public Health. 2018;62(2):143-145.

21. Balajee SA, Arthur R, Mounts AW. Global Health Security: Building Capacities for Early Event Detection, Epidemiologic Workforce, and Laboratory Response. Health Secur. 2016;14(6):424-32. 